\title{
Comparative Effectiveness of Low Density Polypropylene (LDPP) Splint and Fiberglass Cast in Repair of Long Bone Fractures in Canines
}

\author{
Adarsh Bijapur, G.U. Yadav* and D.U. Lokhande
}

Department of Veterinary Surgery and Radiology, Bombay Veterinary College, Parel, Mumbai - 12, Maharashtra Animal and Fishery Sciences University, Nagpur (M.S), India

*Corresponding author

\begin{tabular}{|c|c|}
\hline & B \\
\hline Кеу & \multirow{7}{*}{$\begin{array}{l}\text { Canines suffering from long bone fractures were immobilized by low } \\
\text { density polypropylene (LDPP) splint and fiber glass cast. The study was } \\
\text { conducted in clinical cases of } 12 \text { dogs suffering from long bone fractures. } \\
\text { Animals were divided in two groups viz. Group I: Low density } \\
\text { polypropylene (LDPP) splint (N=6) and Group II: Fiber Glass cast (N=6). } \\
\text { Dogs immobilized with fiberglass casts attained full mobility and complete } \\
\text { weight bearing on fractured limb earlier than the dogs treated with Low } \\
\text { density polypropylene (LDPP) splints. The Cost of immobilization in } \\
\text { Group II was comparatively higher than the cost of implant in Group I. } \\
\text { Comparatively complications were observed more in dogs treated with } \\
\text { fiberglass casts than the dogs with low density polypropylene (LDPP) } \\
\text { splints. }\end{array}$} \\
\hline & \\
\hline & \\
\hline & \\
\hline & \\
\hline & \\
\hline J Jun & \\
\hline
\end{tabular}

\section{Introduction}

Trauma is the common cause of fractures in both small and large animals and is usually due to direct impact from automobile accident, fall from height, dog bites or kicking by the other animals. Repair of long bone fracture in pet animal has made distinct progress in past decade. The high incidence of fracture of long bones in dogs demands cheap but effective method of immobilization (Wilson and Vanderbay, 1995). Long bone fractures are treated by different methods of immobilization like external fixation, internal fixation and immobilization by casting, bracing, or splinting. External co-optation technique is a very useful method of treating the bone fracture as it doesn't disturb internal inflammatory process which favours quicker fracture healing. Numbers of synthetic materials are now days are available for casting which have excellent conforming characteristics such as low density polypropylene and fiberglass. External immobilization technique is a very useful method of treating the bone fracture. It 
doesn't disturb internal inflammatory process which favors quicker fracture healing (Merck, 2006).

\section{Materials and Methods}

The present study was conducted on 12 dogs suffering from long bone fractures. Animals were divided in two groups as Group I: Low density polypropylene splint $(\mathrm{N}=6)$ and Group II: Fiber Glass cast $(\mathrm{N}=6)$.

A detailed case history was recorded for every case in relation to the age, sex, bone involved, etiological factor and type of fracture. The radiographs of affected limbs in both the groups were taken in anterio-posterior and medio-lateral position for each case before and after immobilization, $30^{\text {th }}$ day and $60^{\text {th }}$ day of post immobilization. All the dogs were premedicated with atropine sulphate at the dose rate of $0.04 \mathrm{mg} / \mathrm{kg}$ body weight and dexamethasone at the dose rate of $(0.5 \mathrm{mg} / \mathrm{kg})$ subcutaneously. Each case was sedated with triflupromazine $(1 \mathrm{mg} / \mathrm{kg}) \mathrm{I} / \mathrm{V} 5$ minutes prior to induction with general anaesthesia. Following the sedation with triflupromazine, either thiopentone sodium $(12.5 \mathrm{mg} / \mathrm{kg})$ or propofol5 (3-4 mg/kg) were used as general anaesthetics for both induction and maintenance according to the need of the case. All the animals of group I, the long bone fractures were immobilized with low density polypropylene (LDPP) splints of appropriate size while those of group II were immobilized with fiberglass casts under general anesthesia.

\section{Application of low density polypropylene (LDPP) splints was as follows:}

The anaesthetised dog was placed in lateral recumbancy with fractured limb upside. The fractured limb was held in position and fracture was reduced by applying traction and counter traction maintaining normal angulations of limb. Sufficient quantity of cotton was applied on limb specifically on pressure points including two joints one proximal and one distal to fracture site and the gauze bandage was rolled over it. Low density polypropylene splints those were prepared are taken and Light layer of cotton was kept on the concave surface of splints. Splints were properly placed on the fractured limb and fixed by adhesive tape at proximal, middle and distal part of splint. The crape bandage was then applied over the splints to give additional support to the fractured fragments.. These splints were kept in position for four weeks for simple fractures. In cases of compound fractures, the dressing of wound was done after every alternate day till complete healing of wound and the low density polypropylene (LDPP) splint was properly applied for 6-8 weeks in case of compound fracture. Antibiotic ceftriaxone (25 $\mathrm{mg} / \mathrm{kg}$ ) and meloxicam (0.2-0.3 $\mathrm{g} / \mathrm{kg})$ was administered intramuscularly for 5 days.

\section{Application of fiberglass cast was as follows:}

The anaesthetized dog was placed in lateral recumbency with affected limb upside. The fractured limb was held in position and fracture was reduced by applying traction and counter traction maintaining normal angulations of limb. Sufficient quantity of cotton was applied on limb specifically on pressure points including two joints one proximal and one distal to fracture site and the gauze bandage was rolled over it. Depending upon size of dog the appropriate sized fiberglass cast was selected. Fiberglass cast was immersed in the water having temperature of $20-25^{\circ} \mathrm{C}$ it for 10 seconds. The fiberglass cast was rolled over fractured limb in layers, each layer covering the $50 \%$ of the preceding layer covering two joints, one proximal and one distal to fracture site. Fiberglass was allowed to set for 10-15 minutes. 
The clinical parameters like Acceptability of material, Loosening of splint/cast, Gait on day 1st, 10, 20,30, 60 postoperative, Change in shape of limb on day 10, 20, 30th and 60th day, Time taken for clinical healing of fracture was noted, Time taken to attain full mobility was recorded, Alignment of bone fragments were studied.

\section{Results and Discussion}

Out of twelve clinical cases of dogs with long bone fracture, 9 cases $(75 \%)$ were found below one year of age, and 3 cases $(25 \%)$ were of above one year of age. Automobile accident was recorded as cause for long bone fracture in $9 \operatorname{dogs}(75 \%)$ while fall from height was recorded in $3(25 \%)$ dogs. Similar findings have also been noted by Virkar (1999), Abdulrahman et al., (2003).

In the present study out of 12 animals, six animals $(50 \%)$ were diagnosed with fracture of fore limb and six animals (50\%) with fracture of hind limb. Aithal et al., (1999) observed fracture more frequently in fore limb $(66.67 \%)$ than in hind limb (33.33\%). 7 cases $(58.33 \%)$ were diagnosed as simple oblique fractures and 5 cases $(41.67 \%)$ as simple transverse fractures while in two cases, small lacerated wounds were noticed on skins. Kushwaha et al., (2011) also reported 57.20\% oblique fractures in canines. Seven cases showed mid shaft fractures $(58.33 \%)$, four were distal third fractures $(33.32 \%)$ and one case $(8.33 \%)$ had fracture in proximal third of the bone. Similar findings were recorded by Aithal et al., (1999) and Kushwaha et al., (2011).

Food and water were withheld for 12 hours in all twelve cases of dogs. In all the cases, premedication were performed with atropine sulphate @ $0.04 \mathrm{mg} / \mathrm{kg}$ and dexamethasone @ $0.5 \mathrm{mg} / \mathrm{kg}$ body weight were administered subcutaneously followed by intravenous injection of triflupromazine (1 $\mathrm{mg} / \mathrm{kg})$. General anaesthesia was induced by intravenous injection of thiopentone sodium $(12.5 \mathrm{mg} / \mathrm{kg})$ or propofol (4 mg/kg) according to the need of case. Combination of triflupromazine and propofol provided safe anaesthesia and smooth recovery in young dogs less than 6 months of age but adequate muscle relaxation was not attained while Thiopentone and triflupromazine combination provided good muscle relaxation in dogs more than 6 months age. All the dogs were recovered smoothly in 3 to 4 hours in case of thiopentone and in 1 to 2 hours in case of propofol. Hall and Chamber (1987) opined propofol as one of the best anaesthetic agents in dogs as it produced quiet and rapid induction of anaesthesia as well as smooth and fast recovery.

Application procedure of fiberglass casting was easier and less cumbersome compared to application of Low density polypropylene (LDPP) splints. Low density polypropylene splints were comparatively lighter than fiberglass cast but fiberglass was stronger and durable however, Presence of wounds on fractured limb limited the use of fiberglass where in such cases low density polypropylene splints were provided the advantage of regular dressing of wounds until the wounds heal completely.

Healing of fracture in Group I and Group II was compared based on clinical, radiological, haematological and biochemical observations. Acceptability of material was comparatively better in case of fiberglass casts which may be due to the higher rigidity and light weight of fiberglass cast. Loosening of low density polypropylene (LDPP) splints noted in one case while it was not observed in case of fiberglass casts.

Gait analysis was done in all the cases at regular intervals at 0th, 10th, 20th, 30th and 
60th days post immobilization. On 10th day of post immobilization, four animals of Group I and all six animal of Group II exhibited slight weight bearing on immobilised limb.

On 20th day of post immobilization, five cases of Group II and four cases of Group I showed 'Good' weight bearing i.e. consistent weight bearing with only slight lameness. On 30th day of post immobilization, 'Excellent' weight bearing was noted in three cases of both Group I and Group II respectively. On 60th day of immobilization, all the cases from Group I and Group II showed 'Excellent' weight bearing (Fig. 1-6).

Fig.1\&2 Low density polypropylene (LDPP) splints in placed for radial fracture \& Day 1 post external immobilization with Low density polypropylene (LDPP) splints
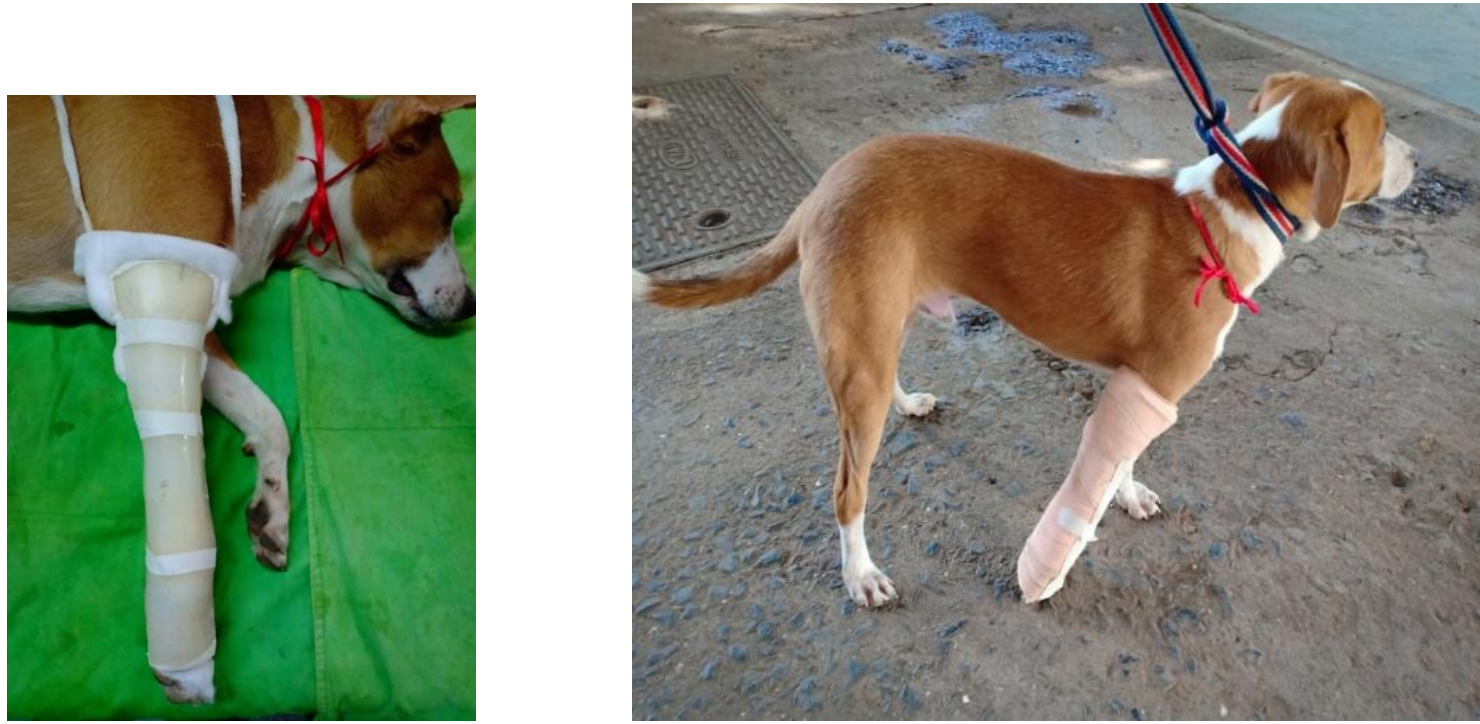

Fig.3\&4 'Excellent' weight bearing by right forelimb on 38th day of post immobilization of LDPP \& Day 1 post external immobilization with Fiberglass Cast
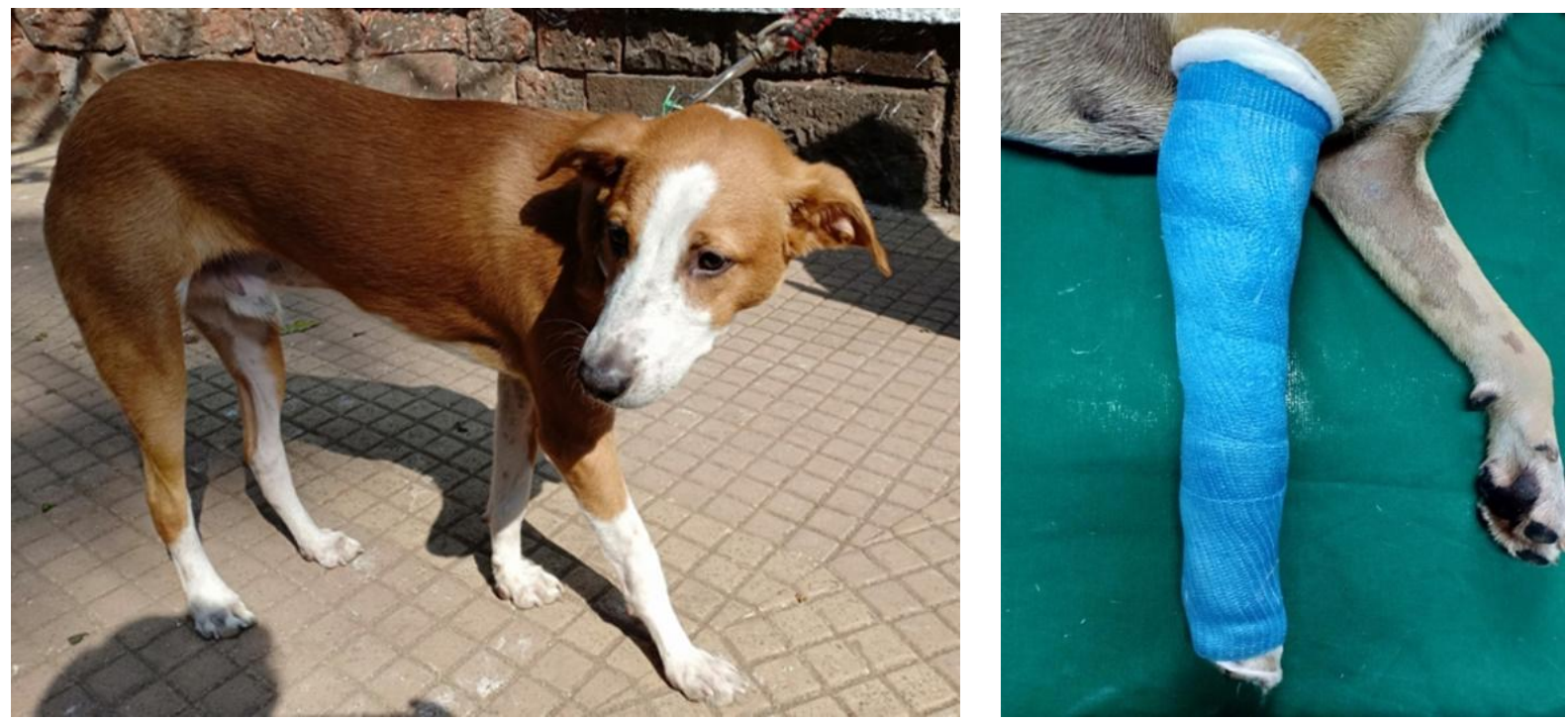
Fig.5\&6 Day 1 post external immobilization with fiberglass cast \& 'Excellent' weight bearing right forelimb on 45th day of post Immobilization with fiberglass cast

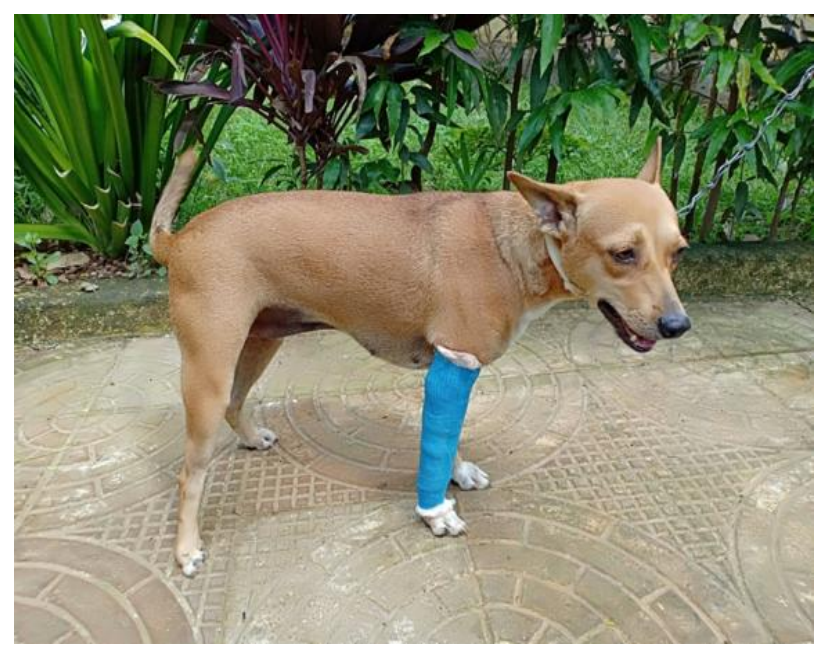

Dogs of Group II attained full mobility and complete weight bearing on fractured limb slightly earlier than the Group I. Dogs of Group I showed full mobility in $44.60 \pm 4.72$ while dogs of Group II attained full mobility in $40.67 \pm 4.80$.

The Cost of immobilization in Group II was comparatively higher than the cost of implant in Group I. Similar observations were also observed by Ayyappan et al., (2009).

The material cost was higher in immobilizing fractures of Group-II than Group I. In group I, the mean cost of LDPP material was Rs. 485 \pm 32.86 whereas in Group II, the mean cost of fiberglass material was Rs. $1050 \pm 89$.44. In the present study more complications were observed in dogs treated with fiberglass casts than the dogs with LDPP splints.

Slight muscular atrophy was noted in 2 cases of fiberglass group and in 1 case of LDPP splint group. Wounds/excoriations at pressure points were noted in 2 cases of dogs treated with fiberglass casts. Similar findings were recorded by Marson and Keenan (1993) and singh et al., (2008).

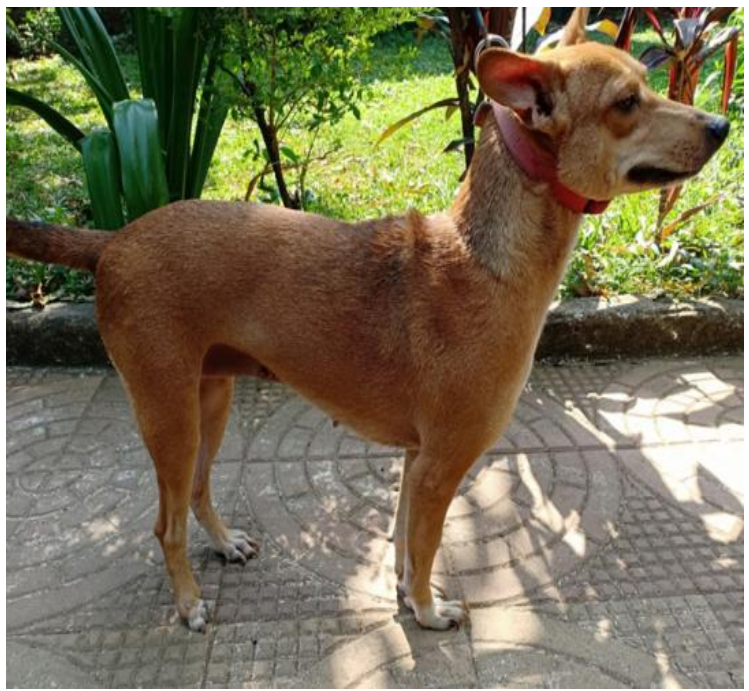

\section{References}

Abdulrahman, H. I., A. Mohammed and M. M. Bukar (2003) A retrospective study of fracture cases presented to university of Maiduguri veterinary teaching hospital. Nigerian Veterinary Journal. 27(3): 25-35.

Aithal, H. P., G. R. Singh and G. S. Bisht (1999) Fractures in dogs: A survey of 402 cases. Indian Journal of Veterinary Surgery, 20(1): 15-21.

Ayyappan, S., Shafiuzama, Md., Ganesh, T.N., Das, B.C. and Suresh Kumar, R. 2009. A clinical study on external fixators for long bone fracture management in dogs. Ind. J. Vet. Surg. 30(2): 90-92.

Hall, L. W. and J. P. Chamber (1987) A clinical trial of propofol infusion anaesthesia in dogs. J. Small. Anim. Prac. 28: 623-637.

Kushwaha, R. B., A. K. Gupta, M. S. Bhadwal, S. Kumar and A. K. Tripathi (2011) Incidence of fractures and their management in animals: A clinical study of 77 cases. Indian Journal of Veterinary Surgery, 32 (1): 54-56. 
Marson, B. M. and M. A. Keenan (1993) Skin surface pressures under short leg casts. Journal of Orthopaedic Trauma, 7(3): 275-8.

Merck, 2006. In: Merck’s Veterinary Manual, 8th edn. Merck and Inc., White House Station, New Jersy, USA.

Singh, V., P. R. Dubi and T. K. Gahlot (2008) Clinical study on efficacy of two selected external immobilization technique for long bone fracture repair in goats (Capra hircus). Intas Polivet. 9
(1): 89-96.

Virkar, S. K. (1999) Comparative study on repair of long bone fracture by using polyvinyl chloride mould and Plaster of Paris cast in goat. M.V.Sc thesis (Surgery and Radiology), Konkan Krishi Vidyapeeth, Dapoli.

Wilson, D. G. and Jr, R. A. Y. Vanderby (1995) An evaluation of six synthetic casting materials: strength of cylinders in bending. Veterinary Surgery, 24(1): 55-59.

\section{How to cite this article:}

Adarsh Bijapur, G.U. Yadav and Lokhande, D.U. 2019. Comparative Effectiveness of Low Density Polypropylene (LDPP) Splint and Fiberglass Cast in Repair of Long Bone Fractures in Canines. Int.J.Curr.Microbiol.App.Sci. 8(06): 119-124.

doi: https://doi.org/10.20546/ijcmas.2019.806.016 